\title{
Bladder granulocytic sarcoma in a child: case report and literature review
}

\author{
Rumeysa Tuna ${ }^{1 \oplus}$, Serap Karaman ${ }^{1 \oplus}$, Tayfun Oktar $^{2 \oplus}$, Sema Anak ${ }^{1 \oplus}$, Öner Doğan ${ }^{3 \oplus}$, \\ Ayşegül Ünüvar ${ }^{1 \oplus}$, Deniz Tuğcu ${ }^{1 \oplus}$, Zuhal Bayramoğlu ${ }^{4 \oplus}$, Suar Çakı Kılıçç \\ Ayça İribaş Çelik ${ }^{6 \odot}$, Zeynep Karakaş ${ }^{1 \oplus}$
}

Departments of ${ }^{1}$ Pediatric Hematology and Oncology, ${ }^{2}$ Urology, ${ }^{3}$ Pathology and ${ }^{4}$ Radiology, Istanbul University Faculty of Medicine, Istanbul; ${ }^{5}$ Department of Pediatric Hematology-Oncology, University of Health Sciences Istanbul Umraniye Training and Research Hospital, İstanbul; ${ }^{6}$ Department of Radiation Oncology, İstanbul University Oncology Institute, İstanbul, Turkey.

\begin{abstract}
Background. Granulocytic sarcoma (GS) is an extramedullary solid tumor composed of immature myeloid cells. GS has been associated with acute myeloid leukemia (AML), myelodysplastic syndromes or myeloproliferative diseases. Although GS can affect various tissues of the human body, it has rarely been reported in other soft tissues such as the breast, gastrointestinal, respiratory and genitourinary tracts. We report a pediatric case diagnosed with granulocytic sarcoma of the bladder and concomitant AML.

Case. A twelve-year-old previously healthy girl was admitted to the pediatric urology clinic with a ten-day history of hematuria and pollakiuria. Laboratory examinations revealed anemia, thrombocytopenia and neutrophilic leukocytosis. Bone marrow aspiration results were consistent with acute myeloid leukemia -FAB subtype M2-. Abdominal magnetic resonance imaging (MRI) showed an irregularly bounded $12 \mathrm{~cm}$ mass on the right side of the bladder. Transurethral resection (TUR) pathology was consistent with granulocytic sarcoma. After a multimodal treatment approach, complete remission was achieved.

Conclusions. Malignant bladder masses are rare causes of macroscopic hematuria in childhood. The diagnostic spectrum is wide, ranging from rhabdomyosarcoma to leukemia involvement. The bladder is a rare site of extramedullary involvement in pediatric patients with AML. Multimodal treatment should be considered on a per-patient basis.
\end{abstract}

Key words: acute myeloid leukemia, children, granulocytic sarcoma, bladder, treatment.

Granulocytic sarcoma (GS) is an extramedullary solid tumor composed of immature myeloid cells. Initially, it was named chloroma as a word originating from greenish color in the 1850s. GS has been associated with acute myeloid leukemia (AML), myelodysplastic syndromes or myeloproliferative diseases. More frequently than in adults, it is seen approximately $10 \%$ concomitantly at the time of diagnosis of pediatric AML. ${ }^{1-3}$ GS can be

\section{Rumeysa Tuna}

rumeysatuna@gmail.com

Received 5th February 2020, revised 16th April 2020, 9th February 2021, 28th February 2021,

accepted 3rd March 2021. seen as isolated extramedullary without bone marrow involvement at the time of primary diagnosis or relapse, can proceed to bone marrow involvement or occur later in the course of primary AML disease. Although GS can affect various tissues, the most frequent extramedullary involvement sites in children are; skin, central nervous system, gingiva, bone and, orbit. ${ }^{1}$ It has rarely been reported in other soft tissues such as the breast, gastrointestinal, respiratory and genitourinary tracts. ${ }^{4-8}$ We report a pediatric case presented with hematuria,diagnosed with granulocytic sarcoma of the bladder and concomitant AML. To our knowledge, this is the 4 th pediatric case of granulocytic sarcoma of the bladder in the 
literature. We presented this case due to its rare involvement site, and to discuss treatment modalities.

\section{Case Report}

A twelve-year-old previously healthy girl was admitted to the pediatric urology clinic with a ten-day history of hematuria and pollakiuria. Family history was unremarkable. Physical examination revealed no abnormality other than paleness. Vital signs were within normal limits. Laboratory examinations revealed anemia (hemoglobin $7.1 \mathrm{gr} / \mathrm{dL}$ ), thrombocytopenia

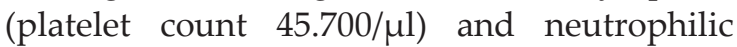
leukocytosis (white blood cell count was 20300/ $\mu \mathrm{l}$, the neutrophil count was $11000 / \mu \mathrm{l}$, lymphocyte count was $6900 / \mu l$, respectively). The erythrocyte sedimentation rate was elevated $(77 \mathrm{~mm} / \mathrm{hr})$. Blood chemistry and coagulation parameters were normal with age-appropriate values. Urine analysis revealed three positive erythrocytes, three positive leukocytes and two positive protein with leukocyte esterase negativity. Pediatric hematology-oncology consultation was requested due to bicytopenia before cystoscopy. Peripheral blood smear revealed no abnormal cells. Bone marrow aspiration showed hypercellular marrow with leukemic infiltration; myeloid blasts with large cytoplasm and occasional granulation were $60 \%$ of bone marrow cells. Immunohistochemical studies demonstrated positive staining for
MPO, lysozyme, CD68, and CD33. Flow cytometry revealed high positivity for $\mathrm{CD}$ 13 and 33. Cytogenetic analysis revealed translocation $\mathrm{t}(8 ; 21)$. Consequently, acute myeloid leukemia -FAB subtype M2- diagnosis was established. Abdominal magnetic resonance imaging (MRI) showed a mass originating from the right side of the bladder wall, extending into the lumen, measuring $12 \mathrm{~cm}$ in diameter and presenting irregular, lobulated margins (Fig. 1a). Transurethral biopsy pathology showed malignant round cell tumor, immunohistochemical studies were consistent with granulocytic sarcoma (Fig. 2). The patient was started on MRC AML 2012 protocol chemotherapy. ${ }^{9}$ After 2 cycles of induction (ADE), bone marrow remission was achieved but pelvic MRI showed residual bladder mass despite marked regression (Fig. $1 b)$. After 4 cycles of chemotherapy $\left(2^{*} \mathrm{ADE}+\right.$ MACE+MidAC) bladder mass persisted. Transurethral resection was performed to clarify the content of the residual mass. Especially due to the special localization of the tumor, pathological evaluation of the mass was preferred before radiotherapy decision. Pathology results confirmed the diagnosis of granulocytic sarcoma. Radiotherapy was planned to the primary tumor location for local control. Bilateral oophoropexy was performed for fertility preservation. Radiotherapy was applied to the bladder region at the dose of 18 Gy in 10 fractions followed by one

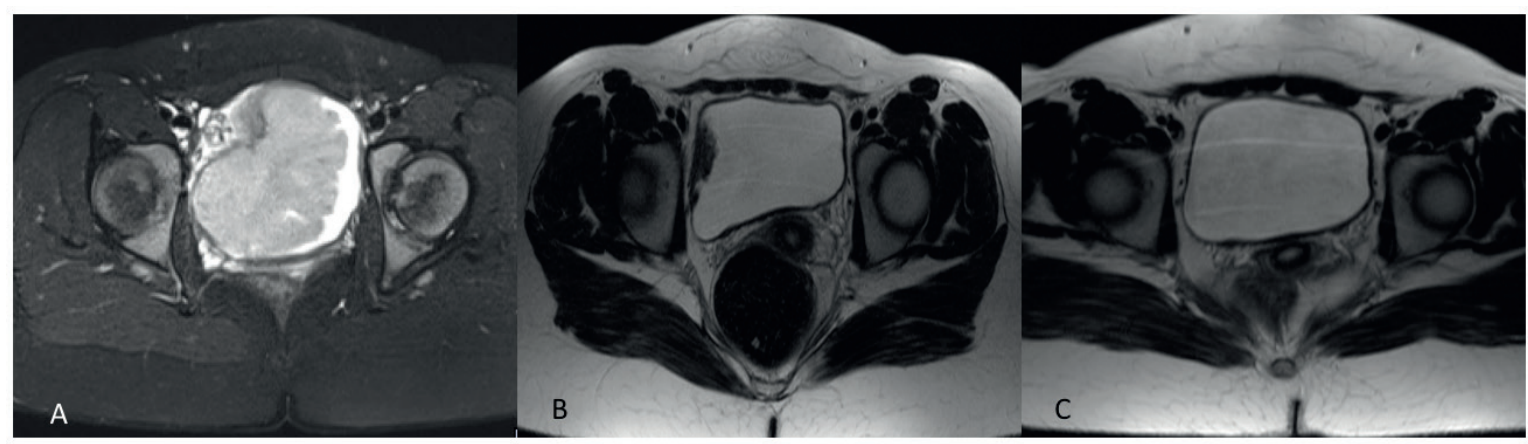

Fig. 1. (A) Initial MR image of bladder mass; T2 weighted fat saturated axial MR image shows hyperintense solid mass with lobulated contour, extending into the bladder lumen. (B) T2 weighted axial image reveals marked regression of the lesion after 2 cycles of induction chemotherapy and (C) total resolution after the end of the treatment. 


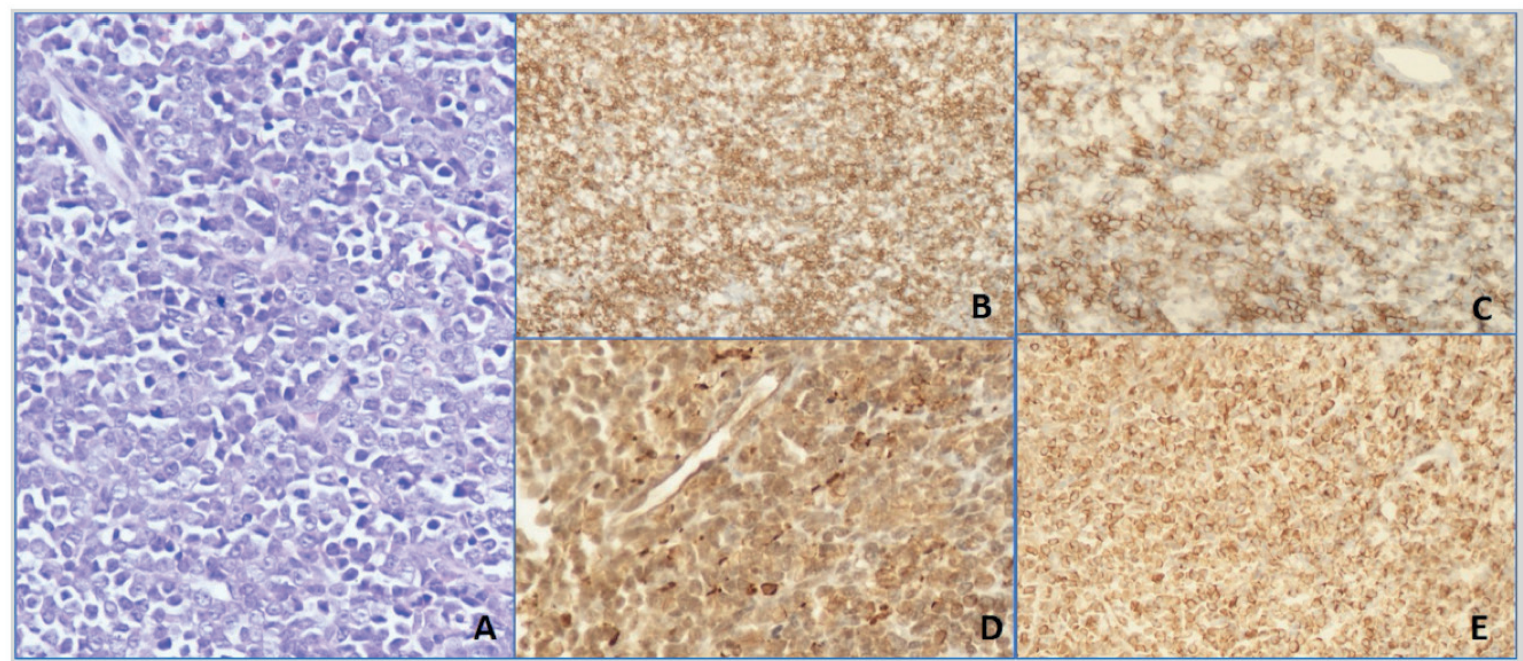

Fig. 2. Transurethral resection pathology: Bladder granulocytic sarcoma (A) Diffuse blastic cell infiltration is seen (H\&amp;E, 40X). Tumor cells were positive with CD117 (B), CD56 (C), CD68 (D) and myeloperoxidase (E).

course of chemotherapy (CLASP). At the end of the chemoradiotherapy, MRI showed total resolution of the bladder mass (Fig. 1c). Considering the incomplete response to treatment with persistence of extramedullary involvement at the end of induction and consolidation chemotherapy, she was stratified as high risk despite favorable genetic features of AML. Therefore hematopoietic stem cell transplantation(HSCT) was approved by the HSCT board. She went to allogeneic HSCT from HLA matched unrelated donor. She remains in complete remission for more than 5 years, outpatient follow up is ongoing. Informed consent for publication of this case was obtained from the children and the parents.

\section{Discussion}

Granulocytic sarcoma is an extramedullary solid tumor composed of myeloid lineage leukemic cells, which can be seen in the course of myeloid leukemia or myeloproliferative disorders. The molecular pathogenesis of the invasion and accumulation of immature cells in various tissues is not fully understood. ${ }^{10}$ It has been shown that invasive acute myelogenous leukemia cell lines have higher expression of matrix metalloproteinase 2-9, membrane type 1 metalloproteinase and tissue inhibitor of metalloproteinase 1-2 compared to normal bone marrow cells and less invasive leukemic cell lines. ${ }^{11-13}$ Higher expression of metalloproteinases was considered to be associated with the invasion and metastasis capacity of solid tumors. ${ }^{14,15}$ It also increases the invasion capacity of leukemia cells and is associated with extramedullary infiltration. ${ }^{11,16}$

In the absence of bone marrow involvement, diagnosing GS can be challenging and requires clinical suspicion. Appropriate immunohistochemical studies are essential for differential diagnosis with non-Hodgkin lymphoma, small round cell tumors and undifferentiated carcinoma, especially for isolated GS. ${ }^{17,18}$ GS with skin involvement is mostly seen in M4 (myelomonocytic) and M5 (monocytic) subtypes of AML, while M2 (mature myeloblastic) is more common in patients with GS in other sites. ${ }^{1,2}$ The most common cytogenetic abnormalities are $\mathrm{t}(8 ; 21)$ (q22;q22) and inv(16)(p13;q22), the latter is associated with extramedullary disease in abdominal sites. ${ }^{18}$ The evidence on the effect of extramedullary involvement on favorable genetic features and prognosis is inadequate. In a study of 84 adult AML patients with $\mathrm{t}(8 ; 21)$ published in 1997, extramedullary involvement was shown to significantly reduce 
survival. ${ }^{19}$ A population-based cohort study on 315 children with AML showed that the presence of extramedullary involvement, which corresponds to $23 \%$ of total cases, significantly reduced 5-year overall survival. ${ }^{20}$

Despite extramedullary infiltration being relatively common in childhood AML compared to adults, there are a few case reports of bladder involvement in children. ${ }^{8,21-23}$ Other rare sites of GS in children are gallbladder, nasal and oral cavity, perineum, small intestine, colon, and testicles.,24-28 It shows different signs and symptoms according to localization. Bladder involvement presents with hematuria, pollakiuria, dysuria, fatigue, pallor, urinary incontinence, urinary retention, suprapubic and flank pain. Obstruction and hydronephrosis can lead to acute renal dysfunction and decreased creatinine clearance.

There are a couple of pediatric cases of granulocytic sarcoma of the bladder in the literature (Table I). The first one was a 16-yearold boy who was previously diagnosed with AML, came with isolated bladder GS after bone marrow transplantation. He was treated with radiotherapy but progressed to AML and died. ${ }^{21}$ The second case was a 4-year-old previously healthy boy who was diagnosed with AML with bladder GS. The primary mass biopsy was not performed but there were myeloid blasts in the urine with flow cytometric examination..$^{22}$ In this case, the presence of myeloid blasts in the urine suggests that leukemic cells may spread within the urinary system, likewise, they do in the cerebrospinal fluid. In this case, remission was achieved with chemotherapy alone. The last case was a 18 month-old previously healthy girl who was diagnosed with bladder GS concomitant with AML. She died with febrile neutropenia after the first cycle of induction chemotherapy. ${ }^{23}$ Our patient who had newly diagnosed bladder GS concomitant with AML had achieved complete remission with 5 courses of chemotherapy, local radiotherapy, and allogeneic hematopoietic stem cell transplantation without serious toxicity.
GS should be treated as AML whether there is bone marrow involvement, or not. Even in isolated GS, progression to AML occurs without systemic therapy. ${ }^{10}$ Multimodal treatment must include combinations of chemotherapy and radiotherapy, surgery or hematopoietic stem cell transplantation on a patient-specific basis. A study from Children's Cancer Group (CCG) including 1832 newly diagnosed pediatric AML patients shows a higher survival rate in patients diagnosed with AML plus GS in the sites other than skin compared with AML plus skin involvement or isolated AML. In the multivariate analysis, other favorable prognostic factors were low initial leukocyte count, female gender and FAB M2 subtype. According to this study, local radiotherapy to tumor sites did not improve the outcome. ${ }^{2}$ However, heterogeneity of the groups with and without radiotherapy constitutes an uncertainty for this result.

In a cohort of 38 adult and child patients with GS, the longest median survival rate with 109 months was observed in patients with genitourinary system involvement compared to other sites. ${ }^{29}$ Local treatment with radiotherapy or surgery should be considered for patients with GS and concurrent AML in case of residual tumor despite bone marrow remission after induction chemotherapy likewise for patients with isolated GS as consolidation. ${ }^{10,30,31}$ Local treatment modalities can also be used as a part of the initial treatment, in case of a need for palliation and symptom relief or relapse, considering tumor size and localization. ${ }^{27,31}$ While lower doses less than 20 Gy are efficient, doses up to $30 \mathrm{~Gy}$ can be used for radiotherapy in children for extramedullary involvement of AML. ${ }^{29}$ Gonad protective measures for fertility preservation should be considered before radiotherapy to the genitourinary region. Several studies show favorable results with allogeneic HSCT in adult patients with GS, pediatric data did not show a clear benefit for survival despite decreased relapse rates. ${ }^{9,32,33}$ For the decision of HSCT in children with AML, reclassification of high-risk patients based on both genetic features and chemotherapy 


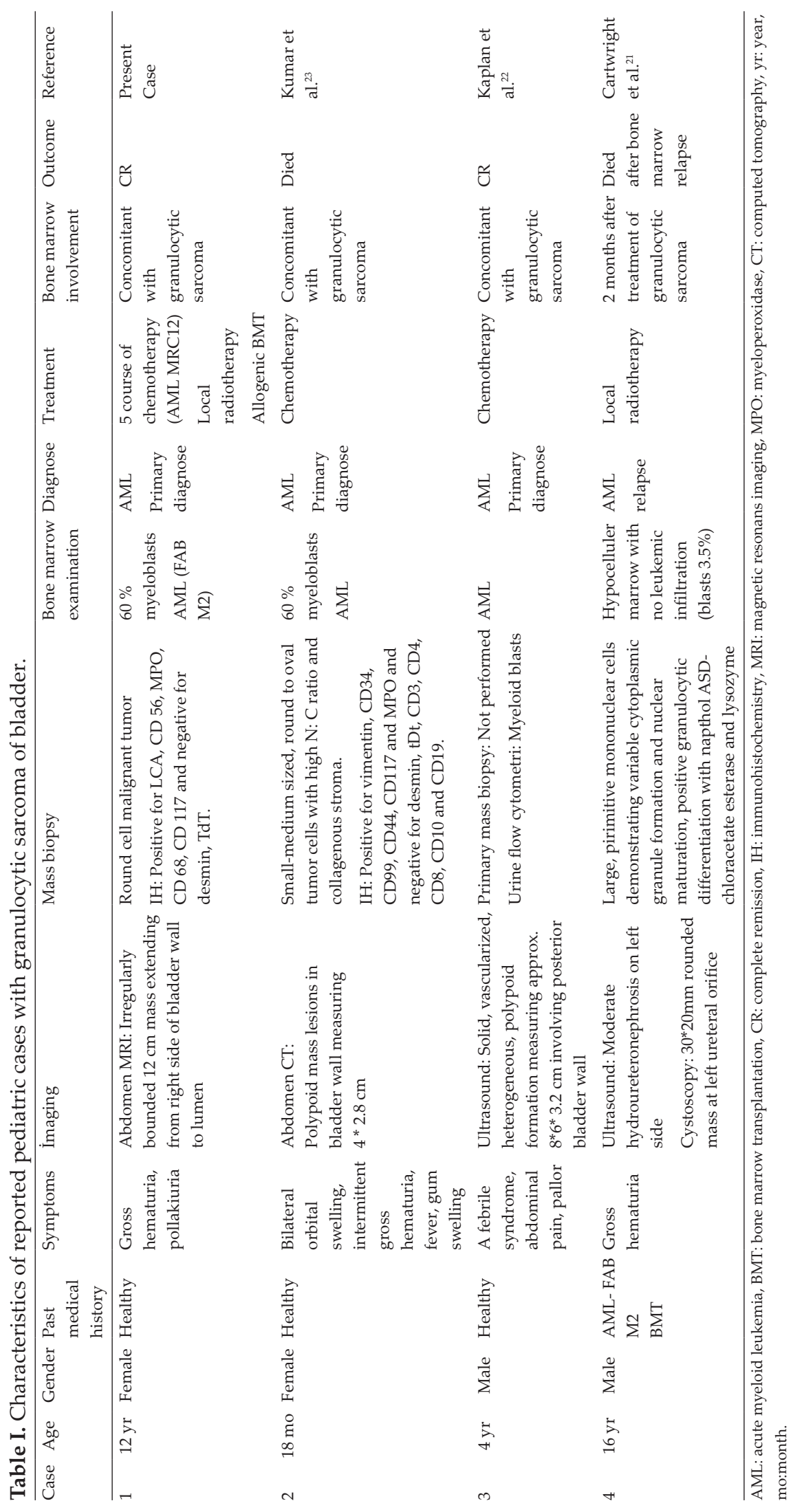


response improves the outcome according to multicenter studies. ${ }^{34,35}$ However the effect of extramedullary tumor response to therapy on the risk groups is not clear. Clinical trials for molecular targeted therapies in selected patients are ongoing. ${ }^{36}$

Malignant bladder masses are rare causes of macroscopic hematuria in childhood. Diagnostic spectrum is wide, ranging from rhabdomyosarcoma to leukemia involvement. The bladder is a rare site of extramedullary involvement in pediatric patients with AML. There is no current clinical consensus guideline for the treatment of this rare disease. Multimodal treatment including chemotherapy, radiotherapy, surgery, hematopoietic stem cell transplantation, and targeted therapies should be considered on a patient-specific basis.

\section{Author contribution}

The authors confirm contribution to the paper as follows: study conception and design: RT, SK; data collection: RT, ZB, ÖD; analysis and interpretation of results: RT, SK, TO, SA, ÖD, AÜ, DT, ZB, SÇK, AIÇ, ZK; draft manuscript preparation: RT, SK. All authors reviewed the results and approved the final version of the manuscript.

\section{Source of funding}

The authors declare the study received no funding.

\section{Conflict of interest}

The authors declare that there is no conflict of interest.

\section{REFERENCES}

1. Kobayashi R, Tawa A, Hanada R, Horibe K, Tsuchida M, Tsukimoto I. Extramedullary infiltration at diagnosis and prognosis in children with acute myelogenous leukemia. Pediatr Blood Cancer 2007; 48: 393-398. https://doi.org/10.1002/pbc.20824
2. Dusenbery KE, Howells WB, Arthur DC, et al. Extramedullary leukemia in children with newly diagnosed acute myeloid leukemia: a report from the Children's Cancer Group. J Pediatr Hematol Oncol 2003; 25: 760-768. https://doi.org/10.1097/00043426200310000-00004

3. Johnston DL, Alonzo TA, Gerbing RB, Lange BJ, Woods WG. Superior outcome of pediatric acute myeloid leukemia patients with orbital and CNS myeloid sarcoma: a report from the Children's Oncology Group. Pediatr Blood Cancer 2012; 58: 519-524. https://doi.org/10.1002/pbc.23201

4. Bekassy AN, Hermans J, Gorin NC, Gratwohl A. Granulocytic sarcoma after allogeneic bone marrow transplantation: a retrospective European multicenter survey. Acute and Chronic Leukemia Working Parties of the European Group for Blood and Marrow Transplantation. Bone Marrow Transplant 1996; 17: 801-808.

5. Merino Moreno J, Nunez Olarte JM, Pico Sambucety JM, Pastor Gomez-Cornejo L, Ortega Nunez A. Granulocytic sarcoma (chloroma) with bladder and breast localizations preceding acute myeloblastic leukemia. Rev Clin Esp 1987; 180: 260-263.

6. Kim LY, Purkey MT, Patel MR, Ghosh A, Hartner L, Newman JG. Primary granulocytic sarcoma of larynx. Head Neck 2015; 37: 38-44. https://doi. org/10.1002/hed.23805

7. Holzwanger EA, Alam Z, Hsu E, Hsu A, Mangano M, Kathman DL. A case of granulocytic sarcoma or extramedullary acute myelomonocytic leukemia of the gallbladder. Am J Case Rep 2018; 19: 1262-1266. https://doi.org/10.12659/AJCR.911390

8. Geok Chin T, Masir N, Noor Hussin H, Mohd Sidik S, Boon Cheok L, Yean T. Myeloid sarcoma of the urinary bladder with cutaneous tumour seeding after percutaneous suprapubic catheterization. Malays J Pathol 2011; 33: 47-51.

9. Gibson BE, Webb DK, Howman AJ, De Graaf SS, Harrison CJ, Wheatley K. Results of a randomized trial in children with Acute Myeloid Leukaemia: medical research council AML12 trial. Br J Haematol 2011; 155: 366-376. https://doi.org/10.1111/j.13652141.2011.08851.x

10. Samborska M, Derwich K, Skalska-Sadowska J, Kurzawa P, Wachowiak J. Myeloid sarcoma in children - diagnostic and therapeutic difficulties. Contemporary Oncology 2016; 20: 444-448. https:// doi.org/10.5114/wo.2016.65602

11. Wang C, Chen Z, Li Z, Cen J. The essential roles of matrix metalloproteinase-2, membrane type 1 metalloproteinase and tissue inhibitor of metalloproteinase- 2 in the invasive capacity of acute monocytic leukemia SHI-1 cells. Leuk Res 2010; 34: 1083-1090. https://doi.org/10.1016/j. leukres.2010.01.016 
12. Janowska-Wieczorek A, Marquez LA, Matsuzaki A, et al. Expression of matrix metalloproteinases (MMP2 and -9) and tissue inhibitors of metalloproteinases (TIMP-1 and -2) in acute myelogenous leukaemia blasts: comparison with normal bone marrow cells. Br J Haematol 1999; 105: 402-411. https://doi. org/10.1111/j.1365-2141.1999.01352.x

13. Ries C, Loher F, Zang C, Ismair MG, Petrides PE. Matrix metalloproteinase production by bone marrow mononuclear cells from normal individuals and patients with acute and chronic myeloid leukemia or myelodysplastic syndromes. Clin Cancer Res 1999; 5: 1115-1124.

14. Westermarck J, Kahari VM. Regulation of matrix metalloproteinase expression in tumor invasion. FASEB J 1999; 13: 781-792. https://doi.org/10.1096/ fasebj.13.8.781

15. Egeblad M, Werb Z. New functions for the matrix metalloproteinases in cancer progression. Nat Rev Cancer 2002; 2: 161-174. https://doi.org/10.1038/ nrc745

16. Li Z, Chen Z, Lu J, et al. Establishment of a nude mice model of human monocytic leukemia with CNS and multiorgan extramedullary infiltration. Eur J Haematol 2006; 77: 128-133. https://doi.org/10.1111/ j.1600-0609.2006.00686.x

17. Alexiev BA, Wang W, Ning $Y$, et al. Myeloid sarcomas: a histologic, immunohistochemical, and cytogenetic study. Diagnostic Pathology 2007; 2: 42. https://doi.org/10.1186/1746-1596-2-42

18. Almond LM, Charalampakis M, Ford SJ, Gourevitch D, Desai A. Myeloid sarcoma: presentation, diagnosis, and treatment. Clin Lymphoma Myeloma Leuk 2017; 17: 263-267. https://doi.org/10.1016/j. clml.2017.02.027

19. Byrd JC, Weiss RB, Arthur DC, et al. Extramedullary leukemia adversely affects hematologic complete remission rate and overall survival in patients with $\mathrm{t}(8 ; 21)(\mathrm{q} 22 ; \mathrm{q} 22)$ : results from Cancer and Leukemia Group B 8461. J Clin Oncol 1997; 15: 466-475. https:// doi.org/10.1200/JCO.1997.15.2.466

20. Stove HK, Sandahl JD, Abrahamsson J, et al. Extramedullary leukemia in children with acute myeloid leukemia: a population-based cohort study from the Nordic Society of Pediatric Hematology and Oncology (NOPHO). Pediatr Blood Cancer 2017; 64: e26520. https://doi.org/10.1002/pbc.26520

21. Cartwright PC, Faye-Petersen O, Bybee B, Snow BW. Leukemic relapse presenting with ureteral obstruction caused by granulocytic sarcoma. J Urol 1991; 146: 1354-1355. https://doi.org/10.1016/S00225347(17)38092-8
22. Kaplan J, Dardanelli E, Sierre S, Moguillansky S, Lipsich J. Granulocytic sarcoma of the urinary bladder in a pediatric patient. J Pediatr Urol 2013; 9: 9-11. https://doi.org/10.1016/j.jpurol.2012.04.010

23. Delhi Kumar CG, Thilagavathy V, Arun Babu T. Granulocytic sarcoma of bladder in an 18-mo-old child with acute myeloid leukemia. Indian J Pediatr 2014; 81: 1118-1119. https://doi.org/10.1007/s12098014-1371-1

24. Anagnostopoulos C, Jadwat Y, Wood NH, et al. A report of oral extramedullary acute myeloid leukaemia (AML) in an 8-year-old girl with newly diagnosed AML-M4Eo. SADJ 2007; 62: 390-393.

25. Siraj F, Kaur M, Dalal V, Khanna A, Khan AA. Myeloid sarcoma: a report of four cases at unusual sites. Ger Med Sci 2017; 15: Doc03. https://doi. org/10.3205/000244

26. Mrad K, Abid L, Driss M, Ben Abid H, Ben Romdhane K. Granulocytic sarcoma of the small intestine in a child without leukemia: report of a case with cytologic findings and immunophenotyping pitfalls. Acta Cytol 2004; 48: 641-644. https://doi. org/10.1159/000326435

27. Lin CH, Wu KH, Lin WC, Tsai JD, Peng CT, Chen AC. Granulocytic sarcoma of the colon in a child with acute myeloid leukemia presenting as hematochezia. J Pediatr Hematol Oncol 2008; 30: 981-983. https:// doi.org/10.1097/MPH.0b013e31818c010c

28. Fonseca A, Scheinemann K, Jansen J, Barr R. Testicular myeloid sarcoma: an unusual presentation of infant acute myeloid leukemia. J Pediatr Hematol Oncol 2014; 36: 155-157. https://doi.org/10.1097/ MPH.0000000000000097

29. Bakst R, Wolden S, Yahalom J. Radiation therapy for chloroma (granulocytic sarcoma). Int J Radiat Oncol Biol Phys 2012;82:1816-1822. https://doi. org/10.1016/j.ijrobp.2011.02.057

30. Bakst RL, Tallman MS, Douer D, Yahalom J. How I treat extramedullary acute myeloid leukemia. Blood 2011; 118: 3785-3793. https://doi.org/10.1182/ blood-2011-04-347229

31. Solh M, Solomon S, Morris L, Holland K, Bashey A. Extramedullary acute myelogenous leukemia. Blood Rev 2016; 30: 333-339. https://doi.org/10.1016/j. blre.2016.04.001

32. Chevallier P, Labopin M, Cornelissen J, Socie G, Rocha V, Mohty M. Allogeneic hematopoietic stem cell transplantation for isolated and leukemic myeloid sarcoma in adults: a report from the Acute Leukemia Working Party of the European group for Blood and Marrow Transplantation. Haematologica 2011; 96: 1391-1394. https://doi.org/10.3324/ haematol.2011.041418 
33. Gibson BE, Wheatley K, Hann IM, et al. Treatment strategy and long-term results in paediatric patients treated in consecutive UK AML trials. Leukemia 2005; 19: 2130-2138. https://doi.org/10.1038/ sj.leu. 2403924

34. Rasche M, Steidel E, Kondryn D, et al. Impact of a risk-adapted treatment approach in pediatric AML: a report of the AML-BFM registry 2012. Blood 2019; 134: 293-293. https://doi.org/10.1182/ blood-2019-130969
35. Sauer MG, Lang PJ, Albert MH, et al. Hematopoietic stem cell transplantation for children with acute myeloid leukemia-results of the AML SCT-BFM 2007 trial. Leukemia 2020; 34: 613-624. https://doi. org/10.1038/s41375-019-0584-8

36. Kolb EA, Meshinchi S. Acute myeloid leukemia in children and adolescents: identification of new molecular targets brings promise of new therapies. Hematology Am Soc Hematol Educ Program 2015; 2015: 507-513. https://doi.org/10.1182/ asheducation-2015.1.507 